\title{
CARACTERIZAÇÃO TECNOLÓGICA E AVALIAÇÃO DE DEPRESSORES NA FLOTAÇÃO DE REJEITO DE MINÉRIO DE FERRO
}

\author{
Geriane Macedo Rocha' \\ Nayara Rilla de Souza Machado' \\ Bianca Trajano dos Santos ${ }^{2}$ \\ Maria Teresa Pedrosa Silva Clerici \\ Carlos Alberto Pereira'
}

\begin{abstract}
Resumo
Os estudos envolvendo rejeitos têm ganhado a atenção da indústria mineral devido a seu potencial de aumento de produção e redução dos passivos ambientais. O material deste estudo é um rejeito de minério de ferro de uma barragem da Mineração Usiminas-MG-Brasil, coletado através de furos de sonda e caracterizado por análises granulométricas, químicas e mineralógicas. Foram realizados ensaios de flotação, avaliando a ação depressora de fubás de milho (Flotamil75 e Flokit4 I5) e farinhas de mandioca (FFO I e FF73), visando obter concentrado para indústria metalúrgica. A distribuição granulométrica indicou $25 \%$ das partículas passantes em $10 \mu \mathrm{m}$ e 15\% retidas em $297 \mu \mathrm{m}$, ajustadas por classificação e deslamagem. Os teores de $\mathrm{Fe}$ e $\mathrm{SiO}_{2}$ do rejeito foram $44,3 \%$ e 30,9\%, respectivamente. Os principais minerais identificados foram hematita e quartzo, e em menor proporção, agregados ferruginosos terrosos. Na análise dos depressores, as farinhas de mandioca apresentaram maior índice de absorção de água e menor $\mathrm{pH}$, comparadas aos fubás de milho. A farinha de mandioca FF73 apresentou o melhor desempenho da flotação, com 75,88\% de recuperação metalúrgica e 2,24\% $\mathrm{SiO}_{2}$ no concentrado.
\end{abstract}

Palavras-chave: Caracterização; Flotação; Rejeito de minério de ferro.

\section{TECHNOLOGICAL CHARACTERIZATION AND EVALUATION OF DEPRESSORS IN THE FLOTATION OF IRON ORE TAILING}

\begin{abstract}
Studies involving tailings have raised mineral industry awareness because of its potential to increases in production as well as a reduction of the environmental liabilities. The main material of this study is an iron ore tailing from the Mineração Usiminas-MG-Brazil dam, collected through probe holes and characterized by size, chemical e mineralogical analyses. Flotation assays were also carried out, evaluating the ground corn (Flotamil75 and Flokit4I5) and cassava flour (FFOI and FF73) depressant action, aiming at achieving a concentrate adequate for use in the metallurgical industry. The size distribution of the tailing indicated $25 \%$ passing $10 \mu \mathrm{m}$ and $15 \%$ above $297 \mu \mathrm{m}$, which was adjusted by classification and desliming. The $\mathrm{Fe}$ and $\mathrm{SiO}_{2}$ contents were $44.3 \%$ and $30.9 \%$, respectively. The main mineral identified were hematite and quartz, and to a lesser extent, ferruginous earthy aggregates. In the analysis of the depressants, the cassava flour presented higher water absorption index and lower $\mathrm{pH}$, compared to ground corn. The cassava flour FF73 reached the best performance in the flotation: metallurgical recovery $75.88 \%$ and $2.24 \% \mathrm{sio}_{2}$ in concentrate.
\end{abstract}

Keywords: Characterization; Flotation; Iron ore tailing.

\section{INTRODUÇÃO}

Além da conhecida exaustão das reservas minerais com alto teor metálico, o cenário econômico dos últimos anos com queda do preço internacional do minério de ferro, tornou ainda mais importante os estudos envolvendo a recuperação de rejeitos. Milhões de toneladas de minerais úteis são descartados anualmente para rejeitos, onerando

'Programa de Pós-graduação em Engenharia Mineral, Departamento de Engenharia de Minas, Universidade Federal de Ouro Preto, MG, Brasil. E-mail: geriane_ufop@hotmail.com

${ }^{2}$ Departamento de Engenharia de Alimentos, Universidade Estadual de Campinas, Campinas, SP, Brasil. 
os custos de operação, aumentando as perdas de produção e o impacto ambiental [I]. Assim como para os minérios, 0 conhecimento das propriedades físicas, químicas e espécies minerais dos rejeitos permite propor rotas de beneficiamento e prever seu comportamento no processo, favorecendo a viabilização de seu reaproveitamento.

Para materiais de granulometria fina, passante em $150 \mu \mathrm{m}$, o principal método de concentração mundialmente aplicado é a flotação, e por isso foi a técnica estudada neste trabalho. A propriedade diferenciadora da flotação é a hidrofobicidade, que pode ser natural ou induzida através da adsorção de reagentes [2]. Na flotação catiônica do minério de ferro, tipicamente, são utilizados a amina como coletor do quartzo e espumante, e o amido gelatinizado, principalmente de milho, como depressor dos minerais de ferro. Pearse [3] explica que os depressores têm a função de bloquear ou blindar a superfície da ganga, evitando a adsorção dos coletores. $\mathrm{O}$ amido consiste de duas frações principais, uma com cadeia linear de moléculas de glicose, denominada amilose e uma sem estrutura definida e altamente ramificada, denominada amilopectina. A proporção amilose:amilopectina não é constante em diferentes vegetais, ou diferentes variedades de um mesmo vegetal e determina algumas das propriedades do amido.

Segundo Denardin e Silva [4] em contato com a água fria pode ocorrer o inchamento dos grãos de amido, mas esse processo é reversível pela secagem. Porém, ao aquecer os grânulos em água, eles incham irreversivelmente num fenômeno denominado gelatinização, processo que envolve a ruptura da estrutura granular, o inchamento, a hidratação e a solubilização das moléculas. Quando é resfriado, o amido gelatinizado pode sofrer a retrogradação. As moléculas de amido vão perdendo energia e as ligações de hidrogênio tornam-se mais fortes, e então as cadeias começam a reassociar-se num estado mais ordenado, o gel vai se tornando mais opaco e tem-se um aumento da viscosidade como consequência da retrogradação.

Amidos que já passaram por processos térmicos apresentam maior capacidade de absorção de água e de solubilidade em água do que o amido cru, que é insolúvel em água [5]. A presença de alguns nutrientes podem afetar as propriedades de gelatinização e formação de pasta, e por isso, por exemplo, é importante fazer a distinção entre farinhas e amidos de um mesmo cereal, pois enquanto as farinhas apresentam teores consideráveis de fibras, proteínas, lipídeos e sais minerais, os amidos devem possuir elevado grau de pureza (menos de $2 \%$ de outros nutrientes) [6,7].

Os processos de obtenção de fubá de milho e farinha de mandioca são diferentes. No caso do milho, o fubá pode ser obtido na forma integral, contendo todas as partes do grão e teor de lipídeos em torno de 1,9\%, ou na forma degerminada, sem o germe, com teor de lipídeo inferior a $0,5 \%$ [8]. A farinha de mandioca poderá conter ou não as partes fibrosas internas da raiz. Ambos passam por processo de secagem, o que também pode afetar as propriedades do amido.
Quando as farinhas/amidos são afetados pelo processamento, algumas análises tornam-se difíceis para indicar a composição, principalmente as de teores de amilose/amilopectina, tamanho e forma dos grânulos, entre outras, pois as interações ocorridas afetam os resultados. Assim, análises como o índice de solubilidade em água e absorção de água, o pH, e a viscosidade de pasta podem ser realizadas para estudo das propriedades tecnológicas do amido [6].

Em comparação com amidos de milho, Breuninger et al. [9] citam que os amidos de mandioca possuem baixo nível de materiais residuais (óleo, proteína, cinzas), menor teor de amilose, consequentemente maior teor de amilopectina, e elevadas massas moleculares de amilose e amilopectina. $\mathrm{O}$ amido de mandioca apresenta tipicamente em torno de 17 a $20 \%$ de amilose e o amido de milho em torno de $25 \%$. Sobre o teor de óleo no amido, segundo Araujo et al. [10], valores acima de $\mathrm{I}, 8 \%$ pode causar a inibição da espuma, sendo esse risco maior se o teor de PPC (perda por calcinação) do minério for alto.

O objetivo desse trabalho foi caracterizar um rejeito de minério de ferro fino, estocado em uma barragem da Mineração Usiminas, quanto à sua distribuição granulométrica e composição química e mineralógica; e propor um processo de concentração que gere um concentrado adequado para aplicação na indústria metalúrgica. A partir da análise de suas características foram realizados ensaios de flotação, avaliando a ação depressora de farinhas de mandioca e fubás de milho, sendo algumas propriedades dessas fontes de amido determinadas em laboratório.

\section{MATERIAIS E MÉTODOS}

O material estudado foi um rejeito de minério de ferro, coletado através de uma campanha de sondagem em uma barragem da Mineração Usiminas, denominada Barragem Central, localizada na região de Serra Azul no Quadrilátero Ferrífero-MG.

\section{I Caracterização e Preparação da Amostra}

A caracterização da amostra foi feita através de análises granulométricas por peneiramento combinado e granulômetro a laser nos Laboratórios do DEMIN/UFOP, análises químicas por fluorescência de raios $\mathrm{X}$ no Laboratório Químico da Mineração Usiminas e análises mineralógicas por difratometria de raios $X$ no Laboratório de Difração de raios $X$ da UFMG e cálculos estequiométricos.

Para alimentação nos ensaios de flotação foi realizado o ajuste da granulometria desse rejeito. A classificação foi através de peneiramento a úmido, em peneiras quadradas com abertura de $297 \mu \mathrm{m}$. A deslamagem foi realizada em baldes transparentes de 20 litros, com percentual de sólidos de $15 \%$ e pH da polpa ajustado em $9,8 \mathrm{com} \mathrm{NaOH}$ ( $5 \% \mathrm{p} / \mathrm{v})$. Após agitação manual com um bastão por 3 minutos, a polpa 
sedimentava por 5 minutos, e então era feito o sifonamento do sobrenadante, sendo esse processo repetido por 3 vezes. O sólido afundado (underflow) foi usado nos testes de flotação.

\subsection{Ensaios de Flotação}

Os ensaios de flotação em bancada foram realizados em duplicata, usando uma célula de fabricação CDC e cuba de $1500 \mathrm{~mL}$. O percentual de sólidos de condicionamento dos reagentes e de flotação foi $45 \%$, velocidade do rotor de I 100 RPM e tempo de coleta do flotado de 5 minutos. O coletor utilizado foi a monoamina Flotigam EDA da Clariant $(1 \% \mathrm{p} / \mathrm{v})$ na dosagem de $100 \mathrm{~g} / \mathrm{t}$. Os moduladores de $\mathrm{pH}$ foram $\circ \mathrm{NaOH}(5 \% \mathrm{p} / \mathrm{v})$ e $\circ \mathrm{CO}_{2}$ gasoso.

$\mathrm{OCO}_{2}$ (dióxido de carbono) foi utilizado considerando que em algumas unidades industriais ele é aplicado no controle de $\mathrm{pH}$ na flotação e no tratamento de água como substituto aos ácidos, devido ao seu manuseio mais seguro. A reação do $\mathrm{CO}_{2}$ com a água forma o ácido carbônico, conforme Equações I e 2, reduzindo o pH da polpa.

$$
\begin{aligned}
& \mathrm{H}_{2} \mathrm{O}+\mathrm{CO}_{2} \leftrightarrow \mathrm{H}_{2} \mathrm{CO}_{3} \\
& \mathrm{H}_{2} \mathrm{CO}_{3(a q)} \leftrightarrow \mathrm{H}_{(a q)}^{+}+\mathrm{HCO}_{3(a q)}^{-}
\end{aligned}
$$

Os tempos de condicionamento do coletor e depressor foram I e 5 minutos, respectivamente. $\mathrm{O}$ pH de flotação foi 10 . Os depressores $(1 \% \mathrm{p} / \mathrm{v})$ foram gelatinizados na proporção amido:soda de 8: I. As condições variadas estão apresentadas na Tabela I.

\subsection{Caracterização dos Fubás de Milho e Farinhas de Mandioca}

As análises dos fubás de milho e farinhas de mandioca, utilizados como fontes de amido nos ensaios de flotação, foram realizadas, em triplicata, no Departamento de Tecnologia de Alimentos/Unicamp. Os índice de absorção de água (IAA) e solubilidade em água (ISA) foram determinados pelo método de Anderson et al. [5], sendo o ISA obtido pelo peso do sobrenadante após secagem dividido pela massa da amostra inicial, posteriormente transformado em \%, e o IAA obtido pela relação entre a massa de resíduo remanescente no tubo após centrifugação e a massa da amostra inicial. $\mathrm{O}$ pH dos fubás e farinhas foi medido conforme descrito nas normas analíticas do Instituto Adolfo Lutz [I I].

\begin{tabular}{|c|c|c|}
\hline \multicolumn{2}{|c|}{ Depressores } & \multirow{2}{*}{ Dosagem $(g / t)$} \\
\hline Produto & Fabricante & \\
\hline Fubá de Milho - Flotamil75 & Caramuru & \\
\hline Fubá de Milho - Flokit4I 5 & Kowalski & 400 \\
\hline Farinha de Mandioca - FFOI & Tecknoamido & 600 \\
\hline Farinha de Mandioca - FF73 & Tecknoamido & \\
\hline
\end{tabular}

Tabela I. Condições experimentais dos ensaios de flotação em bancada
As análises das propriedades de pastas foram realizadas no equipamento Rapid Visco Analyser (RVA), modelo RVA 4500, com o software Thermocline para sistema operacional Windows. A programação totalizou 13 minutos de análise com a seguinte descrição: início a $50^{\circ} \mathrm{C}$ por 60 segundos, desenvolvendo a rampa de aquecimento até $95^{\circ} \mathrm{C} \mathrm{em} 4,8$ minutos, temperatura de $95^{\circ} \mathrm{C}$ mantida por 7,2 minutos, rampa decrescente até $50^{\circ} \mathrm{C}$ em II minutos, e temperatura de $50^{\circ} \mathrm{C}$ mantida até 13 minutos. As informações obtidas através dos perfis viscoamilográficos foram: viscosidade de pico (viscosidade máxima registrada em rampa de aquecimento), trough (menor valor de viscosidade), breakdown (diferença entre viscosidade de pico e menor valor de viscosidade), viscosidade final (valor atingido após a rampa de resfriamento), setback (diferença entre a viscosidade final e o menor valor de viscosidade, temperatura de pasta (temperatura de gelatinização sob rampa de aquecimento).

\section{RESULTADOS E DISCUSSÃO}

\section{I Caracterização do Rejeito de Minério de Ferro}

A distribuição granulométrica do rejeito, conforme amostrado em campo, e após preparo para os testes de flotação, são apresentadas na Figura I. O material passante em $10 \mu \mathrm{m}$ foi aproximadamente $25 \%$ do rejeito, sendo por isso indicada a sua deslamagem antes da alimentação nos testes de flotação, cujo percentual de lama chegou, então, a aproximadamente $10 \%$. Com relação às frações grosseiras, foi necessário um escalpe em $297 \mu \mathrm{m}$, ajustando a granulometria para no máximo $10 \%$ retido em $150 \mu \mathrm{m}$. A ampla faixa de tamanho na alimentação pode comprometer a seletividade do processo em função de diferenças de comportamento como hidrofobicidade, área superficial específica e peso [12]. Assim, usualmente os processos de flotação de minério de ferro são alimentados por partículas na faixa de $-150 \mu \mathrm{m}+10 \mu \mathrm{m}$.

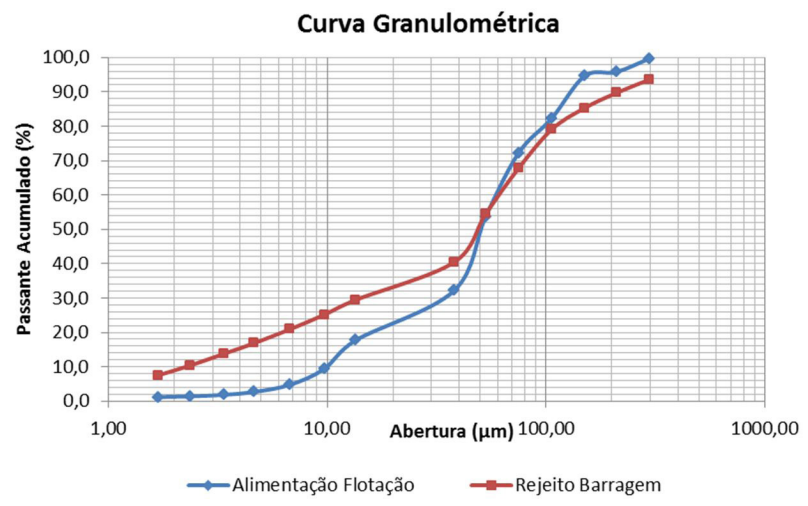

Figura I. Distribuição granulométrica da amostra de rejeito da Barragem Central e da alimentação da flotação. 
No processo para ajuste da granulometria, as partições de massa para retido do peneiramento foi $6 \%$, do overflow da deslamagem $15 \%$, e do underflow da deslamagem ou alimentação da flotação foi $79 \%$.

As análises químicas do rejeito (Tabela 2) mostraram que os percentuais de ferro e sílica eram similarmente distribuídos nas frações acima de $38 \mu \mathrm{m}$, sendo a maior concentração de ferro e a menor de sílica na fração menor que $38 \mu \mathrm{m}$. O maior teor de alumina foi encontrado na fração $-38 \mu \mathrm{m}$. O PPC apresentou proporção elevada na fração mais grosseira $(+150 \mu \mathrm{m})$ e mais fina $(-38 \mu \mathrm{m})$.

Após as etapas de classificação e deslamagem houve uma redução significativa nos teores dos contaminantes $\mathrm{Al}_{2} \mathrm{O}_{3}$, PPC, P e Mn (Tabela 3). Essa redução era esperada, já que esses contaminantes estavam mais presentes nas frações extremas $(+150 \mu \mathrm{m}$ e $-38 \mu \mathrm{m})$ do rejeito, e foram então, descartados no retido do peneiramento, e no overflow da deslamagem, conforme Tabela 4.

Através da difratometria de raios $X$ do rejeito foram identificados somente os minerais hematita e quartzo em todas as frações analisadas. Apesar do teor de PPC elevado na fração fina do rejeito, minerais hidratados não foram identificados. Outras fases minerais podem não ter sido identificadas por se apresentarem em concentrações abaixo do limite de detecção dessa técnica, ou em função de sobreposição de picos.

Então, para maior compreensão dos resultados, conhecendo as principais fases minerais primárias e secundárias presentes nos minérios de ferro do Quadrilátero Ferrífero (magnetita, hematita, goethita, quartzo, caulinita, óxido de manganês e gibsita), conforme foram citadas por Arroyo [13], foi feita a quantificação das espécies mineralógicas a partir de cálculos estequiométricos (Tabela 5). Porém, essa técnica considera apenas a composição química, não sendo possível a diferenciação, por exemplo, entre goethita e goethita terrosa. Assim, o elevado PPC nas frações $+150 \mu \mathrm{m}$ e $-38 \mu \mathrm{m}$ pode estar associado à presença de goethita terrosa (hidróxido de ferro amorfo), que por não apresentar estrutura cristalina, não foi identificada na difração de raios $X$.

Tabela 2. Análise granuloquímica da amostra de rejeito da Barragem Central

\begin{tabular}{|c|c|c|c|c|c|c|c|c|c|}
\hline \multirow{2}{*}{$\begin{array}{c}\text { Fração } \\
(\mu \mathrm{m})\end{array}$} & \multirow{2}{*}{ Retido (\%) } & \multicolumn{6}{|c|}{ Teores (\%) } & \multicolumn{2}{|c|}{ Distribuição (\%) } \\
\hline & & $\mathbf{F e}$ & $\mathrm{SiO}_{2}$ & $\mathbf{P}$ & Mn & $\mathrm{Al}_{2} \mathrm{O}_{3}$ & PPC & $\mathbf{F e}$ & $\mathrm{SiO}_{2}$ \\
\hline+150 & 14,69 & 40,22 & 36,64 & 0,052 & 0,044 & 2,19 & 2,43 & 13,34 & 17,40 \\
\hline$-150+53$ & 30,77 & 43,04 & 35,31 & 0,027 & 0,078 & 1,08 & 0,97 & 29,89 & 35,12 \\
\hline$-53+38$ & 14,09 & 40,80 & 38,51 & 0,028 & 0,016 & 1,46 & $\mathrm{I}, 40$ & 12,98 & 17,54 \\
\hline-38 & 40,45 & 47,97 & 22,89 & 0,055 & 0,033 & 4,39 & 3,18 & 43,80 & 29,93 \\
\hline Global & 100,00 & 44,30 & 30,93 & 0,042 & 0,046 & 2,64 & 2,14 & 100,00 & 100,00 \\
\hline
\end{tabular}

Tabela 3. Análise granuloquímica da amostra de alimentação da flotação em bancada

\begin{tabular}{|c|c|c|c|c|c|c|c|c|c|}
\hline \multirow{2}{*}{$\begin{array}{c}\text { Fração } \\
(\mu \mathrm{m})\end{array}$} & \multirow{2}{*}{ Retido (\%) } & \multicolumn{6}{|c|}{ Teores (\%) } & \multicolumn{2}{|c|}{ Distribuição (\%) } \\
\hline & & $\mathbf{F e}$ & $\mathrm{SiO}_{2}$ & $\mathbf{P}$ & Mn & $\mathrm{Al}_{2} \mathrm{O}_{3}$ & PPC & $\mathbf{F e}$ & $\mathrm{SiO}_{2}$ \\
\hline+150 & 7,76 & 37,07 & 43,23 & 0,034 & 0,034 & $\mathrm{I}, 77$ & I,78 & 6,59 & 9,68 \\
\hline$-150+38$ & 59,92 & 40,97 & 39,03 & 0,025 & 0,012 & 0,91 & $\mathrm{I}, 3$ & 56,25 & 67,51 \\
\hline-38 & 32,32 & 50,18 & 24,44 & 0,028 & 0,022 & 1,49 & 2,04 & 37,16 & 22,80 \\
\hline Global & 100,00 & 43,64 & 34,64 & 0,027 & 0,017 & 1,16 & 1,58 & 100,00 & 100,00 \\
\hline
\end{tabular}

Tabela 4. Análise química do retido no peneiramento e overflow da deslamagem

\begin{tabular}{|c|c|c|c|c|c|c|}
\hline \multirow{2}{*}{ Fluxo } & \multicolumn{6}{|c|}{ Teores (\%) } \\
\hline & $\mathbf{F e}$ & $\mathrm{SiO}_{2}$ & $\mathbf{P}$ & Mn & $\mathrm{Al}_{2} \mathrm{O}_{3}$ & PPC \\
\hline Retido peneiramento & 41,73 & 34,01 & 0,065 & 0,070 & 2,65 & 3,17 \\
\hline Overflow deslamagem & 42,92 & 17,84 & 0,117 & 0,077 & ||$, 5 \mid$ & 8,18 \\
\hline
\end{tabular}

Tabela 5. Mineralogia a partir de cálculos estequiométricos do rejeito

\begin{tabular}{|c|c|c|c|c|c|}
\hline Minerais & $+150 \mu \mathrm{m}$ & $-150 \mu \mathrm{m}+53 \mu \mathrm{m}$ & $-53 \mu \mathrm{m}+38 \mu \mathrm{m}$ & $-38 \mu \mathrm{m}$ & Global \\
\hline Magnetita & $0,7 \%$ & $0,8 \%$ & $0,6 \%$ & $0,4 \%$ & $0,6 \%$ \\
\hline Caulinita & $5,5 \%$ & $2,7 \%$ & $3,7 \%$ & I I, I\% & $6,7 \%$ \\
\hline Gibsita & $0,0 \%$ & $0,0 \%$ & $0,0 \%$ & $0,0 \%$ & $0,0 \%$ \\
\hline Goethita ou Goethita Terrosa & $16,4 \%$ & $5,8 \%$ & $8,7 \%$ & $16,1 \%$ & $12,0 \%$ \\
\hline Hematita & $42,1 \%$ & $55,4 \%$ & $49,8 \%$ & $53,7 \%$ & $51,9 \%$ \\
\hline Óxido de Manganês & $0,1 \%$ & $0,1 \%$ & $0,0 \%$ & $0,1 \%$ & $0,1 \%$ \\
\hline Quartzo & $34,1 \%$ & $34,0 \%$ & $36,8 \%$ & $17,7 \%$ & $27,8 \%$ \\
\hline
\end{tabular}




\subsection{Ensaios de Flotação}

A Figura 2 mostra os resultados dos ensaios de flotação, variando-se o tipo de amido e suas dosagens. Os resultados positivos com teor de sílica no concentrado abaixo da especificação da empresa de $2,69 \%$ no pellet feed, indicaram que a flotação levou a bons resultados na concentração desse rejeito. A farinha de mandioca FF73 apresentou o melhor desempenho, alcançando recuperação metálica e teor de $\mathrm{SiO}_{2}$ no concentrado de $75,88 \%$ e $2,24 \%$, respectivamente. O fubá de milho Flotamil75 foi pouco seletivo e obteve as menores recuperações e maiores teores de sílica no concentrado. $\mathrm{O}$ aumento da dosagem teve efeito mais significativo sobre a recuperação metálica para as farinhas de mandioca.

\subsection{Caracterização dos Fubás de Milho e Farinhas de Mandioca}

$\mathrm{Na}$ Tabela 6 são apresentadas as principais características informadas pelos fabricantes dos reagentes testados. Observou-se que conforme diferenciação feita por Breuninger et al. [9] as farinhas de mandioca tenderam a apresentar menores teores de óleo e de proteína do que os

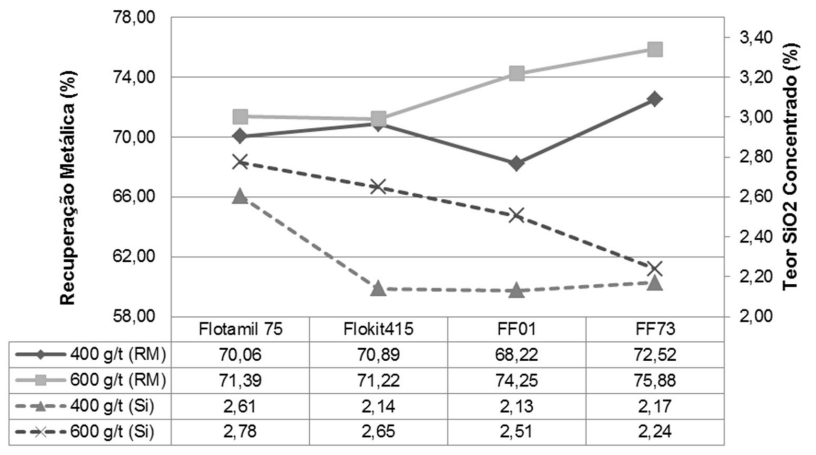

Figura 2. Resultados dos ensaios de flotação em bancada. fubás de milho, e isso pode ter favorecido os resultados na flotação. A essa característica se soma o fato da farinha de mandioca FF73 ter apresentado uma elevada especificação de teor de fração amilácea, o que pode ter contribuído para seu destaque positivo nas variáveis respostas avaliadas. $O$ teor de óleo apresentado pelos fubás indica que provavelmente eles foram preparados com composição integral. A diferença de fração amilácea de uma farinha de mandioca para a outra pode ser devido à maior teor de fibras na FFOI.

Os resultados dos índices de absorção em água (IAA), solubilidade em água (ISA) e pH estão na Tabela 7. O ISA reflete a presença de sólidos solúveis na água fria. Enquanto os valores de ISA sempre aumentam com o cozimento do amido, até ele ficar completamente dextrinizado, os valores de IAA fazem uma curva, em que quando o amido é cru ele é baixo, cresce com o aumento do amido gelatinizado e reduz com um processo contínuo de agitação e cozimento. O IAA pode indicar se $o$ amido irá formar uma rede tridimensional com inúmeras ligações com a água, tornando-se capaz de adsorver nutrientes, minerais e outros compostos nessa rede. Já o ISA indica o contrário, pois quanto maior este índice, mais frágil é esta rede [14].

As farinhas de mandioca apresentaram maiores valores de IAA comparados aos fubás de milho, indicando que elas absorvem maior teor de água fria. Isso foi perceptível no momento da preparação desse reagente, quando era observado que a primeira água que era acrescentada para sua homogeneização, antes do acréscimo de $\mathrm{NaOH}$, era sugada muito rapidamente no caso das farinhas de mandioca.

Quanto ao ISA os valores obtidos foram similares para todos os reagentes, assim como foi apresentado por Sousa [15]. Pelos resultados de IAA e ISA, verificou-se que as farinhas de mandioca analisadas foram capazes de formar uma rede tridimensional com água de melhor poder de retenção que os fubás analisados. Observou-se também que os fubás de milho provavelmente apresentaram maior teor de amido cru em relação às farinhas de mandioca, que deve ter sofrido tratamento térmico durante $\circ$ processo de secagem.

Tabela 6. Amidos e suas principais características informadas pelos fabricantes

\begin{tabular}{lccccc}
\hline \multicolumn{1}{c}{ Reagente } & $+\mathrm{I}, \mathbf{0 ~} \mathbf{~ m m}(\%)$ & $\mathbf{+ 0 , 5 9} \mathbf{~ m m ~ ( \% )}$ & Óleo (\%) & Amido (\%) & Proteína (\%) \\
\hline Fubá de Milho - Flotamil 75 & $\mathrm{I}, 0(\max )$ & $\mathrm{I} 2,0(\max )$ & $\mathrm{I}, 8(\max )$ & $75,0-80,0$ & - \\
Fubá de Milho - Flokit 4I5 & - & $4,0(\max )$ & $\mathrm{I}, 5(\max )$ & $83,0(\min )$ & $7,0(\mathrm{max})$ \\
Farinha de Mandioca - FFOI & 2,49 & - & 0,45 & 75,00 & - \\
Farinha de Mandioca - FF73 & 2,72 & - & 0,45 & 82,57 & - \\
\hline
\end{tabular}

Tabela 7. Análises de IAA, ISA e pH dos depressores

\begin{tabular}{lccc}
\hline \multicolumn{1}{c}{ Reagentes } & IAA (g/g) & ISA (\%) & pH \\
\hline Fubá de Milho - Flotamil 75 & 2,92 & 4,04 & 5,88 \\
Fubá de Milho - Flokit 4I5 & 2,79 & 3,17 & 5,96 \\
Farinha de Mandioca - FFOI & 7,60 & 3,22 & 4,69 \\
Farinha de Mandioca - FF73 & 6,19 & 4,35 & 4,68 \\
\hline
\end{tabular}


Tabela 8. Análise de viscosidade dos depressores

\begin{tabular}{ccccccc}
\hline Reagentes & $\begin{array}{c}\text { Viscosidade } \\
\text { Máxima (cP) }\end{array}$ & $\begin{array}{c}\text { Viscosidade } \\
\text { Mínima (cP) }\end{array}$ & Breakdown (cP) & $\begin{array}{c}\text { Setback } \\
\text { Retrogradação } \\
\text { (cP) }\end{array}$ & $\begin{array}{c}\text { Viscosidade } \\
\text { Final (cP) }\end{array}$ & $\begin{array}{c}\text { Temperatura de } \\
\text { Pasta }\end{array}$ \\
\hline Flotamil 75 & 2132 & 2094 & 38 & 5138 & 7232 & 83,65 \\
Flokit 4I5 & 4486 & 2988 & 1498 & 5285 & 8273 & 73,68 \\
FF0I & 5767 & 919 & 4849 & 242 & 1161 & 50,17 \\
FF73 & 3982 & 3060 & 922 & 4686 & 7746 & 71,00 \\
\hline
\end{tabular}

Em relação ao pH, as amostras de farinha de mandioca apresentaram $\mathrm{pH}$ mais ácido que as demais, indicando que elas tendem a apresentar maior número de íons hidrogênios quando misturadas a água e podem requerer maior adição de hidróxido de sódio para ajuste do $\mathrm{pH}$ de condicionamento e flotação da polpa. $\mathrm{O}$ pH mais ácido da farinha de mandioca indica processos fermentativos que produzem ácidos orgânicos e diminuem o pH da amostra.

As informações obtidas através dos perfis viscoamilográficos estão apresentadas na Tabela 8 . Os dados de viscosidade mostraram que as farinhas de mandioca e fubás de milho não apresentaram viscosidade a frio, mas quando foram aquecidos, a viscosidade aumentou (viscosidade máxima). Quando as amostras passaram por resfriamento ocorreu um aumento da viscosidade, com exceção da farinha FFOI, que apresentou uma redução da viscosidade ao final da rampa de resfriamento (viscosidade final) durante a agitação, o que indica que o amido foi facilmente hidrolisado.

A farinha $\mathrm{FFOI}$ aumentou sua viscosidade à temperatura de pasta de $50^{\circ} \mathrm{C}$, que representa a temperatura de gelatinização da amostra. Este valor é menor comparado aos outros depressores, o que pode ser indício de menor teor de amido cru em sua composição e/ou de gelatinização parcial desse amido.

\section{CONCLUSÕES}

$O$ rejeito pode ser caracterizado como tendo 0 quartzo como o principal mineral de ganga, a hematita como principal mineral-minério, e em menor proporção, agregados ferruginosos terrosos. Pela análise granulométrica a amostra apresentou $15 \%$ retido em $150 \mu \mathrm{m}$ e $25 \%$ passante em $10 \mu \mathrm{m}$. A análise química global da amostra apresentou teores de $44,3 \%$ de $\mathrm{Fe}, 30,9 \%$ de $\mathrm{SiO}_{2}, 2,6 \%$ de $\mathrm{Al}_{2} \mathrm{O}_{3}$ e 2, $1 \%$ de PPC.

Para uma rota de processo com flotação é necessário classificar e deslamar a amostra para ajuste da granulometria, sendo que essas etapas foram responsáveis por uma redução significativa nos teores dos contaminantes $\mathrm{P}, \mathrm{Mn}, \mathrm{Al}_{2} \mathrm{O}_{3}$ e PPC.

A concentração por flotação desse rejeito apresentou resultados positivos, obtendo uma recuperação metálica de $75,88 \%$ e teor de sílica no concentrado de $2,24 \%$, utilizando como depressor a farinha de mandioca FF73 na dosagem $600 \mathrm{~g} / \mathrm{t}$.

Nos ensaios de flotação em bancada os resultados não indicaram uma distinção clara entre o efeito dos fubás de milho e farinhas de mandioca, comprovando que, além da fonte botânica, outros fatores influenciaram no comportamento dos mesmos.

$\mathrm{Na}$ análise de propriedades dos depressores observou-se que as farinhas de mandioca possuem maior índice de absorção de água, índice de solubilidade similar e menor $\mathrm{pH}$, comparadas aos fubás de milho. Os dados de viscosidade da pasta mostraram que as viscosidades dos reagentes aumentam quando aquecidos. Com exceção da farinha FFOI, o aumento da viscosidade dos reagentes é ainda mais significativo quando são resfriados, indício de retrogradação do amido presente.

\section{Agradecimentos}

Os autores agradecem à Universidade Federal de Ouro Preto, Universidade Estadual de Campinas, Associação Brasileira de Metalurgia, Materiais e Mineração (ABM) e Mineração Usiminas, Clariant, Caramuru, Kowalki e Tecknoamido.

\section{REFERÊNCIAS}

I Praes PE, Alburquerque RO, Luz AFO. Recovery of tailings by column flotation. Journal of Minerals \& Materials Characterization \& Engineering. 2013;1:212-216.

2 Rao SR. Surface chemistry of froth flotation - Reagents and mechanisms. Library of congress. 2nd ed. New York: Kluwer Academic/Plenum Publishers; 2004.

3 Pearse MJ. An overview of the use of chemical reagents in mineral processing. Minerals Engineering. 2005; 18:139149. 
Rocha et al.

4 Denardin CC, da Silva LP. Estrutura dos grânulos de amido e sua relação com propriedades físico-químicas. Revista Científica Rural. 2009;39(3):945-954.

5 Anderson RA, Conway HF, Pfeifer VF, Griffin EL Jr. Gelatinization of corn grits by roll-and extrusion-cooking. Cereal Science Today. 1969; 14(I):44-II.

6 Eliasson AC. Starch in food - Structure, function and applications. New York: CRC Press; 2004.

7 BeMiller J, Whistler, R. Starch: Chemistry and Technology. 2. ed. Lincoln: Elsevier Inc; 2009.

8 Núcleo de Estudos e Pesquisas em Alimentação. Universidade Estadual de Campinas. TACO: Tabela brasileira de composição de alimentos. 4. ed. Campinas: Nepaunicamp; $201 \mathrm{I}$.

9 Breuninger WF, Piyachomkwan K, Sriroth K. Tapioca/Cassava starch: production and use. In: Bemiller J, Whistler R. Starch chemistry and technology. 2. ed. Lincoln: Elsevier Inc.; 2009. p. 54I-564.

10 Araujo AC, Viana PRM, Peres AEC. Reagents in iron ores flotation. Minerals Engineering. 2005; 18:2 19-224.

I I Normas Analíticas do Instituto Adolfo Lutz. Métodos químicos e físicos para análises de alimentos. 3. ed. São Paulo: IMESP; 1985.

12 Lima NP, Valadão GE. Avaliação do efeito da granulometria no processo de flotação. Revista da Escola de Minas. 2008;61:473-477.

13 Arroyo CEO. Caracterização geometalúrgica e modelagem geoestatística da mina de Brucutu. [tese]. Ouro Preto: Universidade Federal de Ouro Preto; 2014.

14 Harper JM. Food extrusion. Critical Reviews in Food Science and Nutrition. 1979; I I (2): I55-2 15.

15 Sousa DN. Depressores alternativos na flotação catiônica reversa de minério de ferro. [dissertação]. Catalão: Universidade Federal de Goiás; 2016.

Recebido em: 22 Jan. 2018

Aceito em: 09 Abr. 2018 